\title{
Multiple Comorbidities of 21 Psychological Disorders and Relationships With Psychosocial Variables: A Study of the Online Assessment and Diagnostic System Within a Web-Based Population
}

Ali M AL-Asadi ${ }^{1,2}$, MA, MSc; Britt Klein ${ }^{3,4}$, DPsych (Clinical); Denny Meyer ${ }^{1}$, DBL

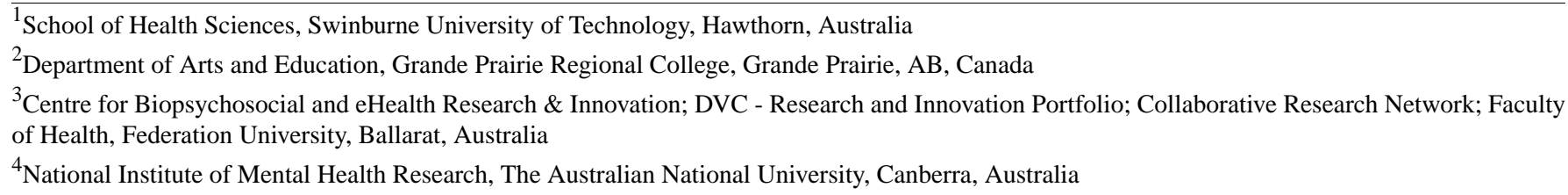

\section{Corresponding Author:}

Ali M AL-Asadi, MA, MSc

Department of Arts and Education

Grande Prairie Regional College

10726 - 106 Ave.

Grande Prairie, AB, T8V 4C4

Canada

Phone: 17805392061

Fax: 17805380960

Email: aalasadi@gprc.ab.ca

\begin{abstract}
Background: While research in the area of e-mental health has received considerable attention over the last decade, there are still many areas that have not been addressed. One such area is the comorbidity of psychological disorders in a Web-based sample using online assessment and diagnostic tools, and the relationships between comorbidities and psychosocial variables.
\end{abstract}

Objective: We aimed to identify comorbidities of psychological disorders of an online sample using an online diagnostic tool. Based on diagnoses made by an automated online assessment and diagnostic system administered to a large group of online participants, multiple comorbidities (co-occurrences) of 21 psychological disorders for males and females were identified. We examined the relationships between dyadic comorbidities of anxiety and depressive disorders and the psychosocial variables sex, age, suicidal ideation, social support, and quality of life.

Methods: An online complex algorithm based on the criteria of the Diagnostic and Statistical Manual of Mental Disorders, 4th edition, Text Revision, was used to assign primary and secondary diagnoses of 21 psychological disorders to 12,665 online participants. The frequency of co-occurrences of psychological disorders for males and females were calculated for all disorders. A series of hierarchical loglinear analyses were performed to examine the relationships between the dyadic comorbidities of depression and various anxiety disorders and the variables suicidal ideation, social support, quality of life, sex, and age.

Results: A 21-by-21 frequency of co-occurrences of psychological disorders matrix revealed the presence of multiple significant dyadic comorbidities for males and females. Also, for those with some of the dyadic depression and the anxiety disorders, the odds for having suicidal ideation, reporting inadequate social support, and poorer quality of life increased for those with two-disorder comorbidity than for those with only one of the same two disorders.

Conclusions: Comorbidities of several psychological disorders using an online assessment tool within a Web-based population were similar to those found in face-to-face clinics using traditional assessment tools. Results provided support for the transdiagnostic approaches and confirmed the positive relationship between comorbidity and suicidal ideation, the negative relationship between comorbidity and social support, and the negative relationship comorbidity and quality of life.

Trial Registration: Australian and New Zealand Clinical Trials Registry ACTRN121611000704998; http://www.anzctr.org.au/trial_view.aspx?ID=336143 (Archived by WebCite at http://www.webcitation.org/618r3wvOG) 
(J Med Internet Res 2015;17(3):e55) doi: 10.2196/jmir.4143

\section{KEYWORDS}

comorbidity; multiple comorbidities; co-occurrences; e-mental health; online; fully automated; generalized anxiety disorder; obsessive-compulsive disorder; social anxiety disorder; posttraumatic stress disorder; panic disorder, major depressive episode; insomnia, hypersomnia, dependency; alcohol; drug; suicidal ideation; social support; quality of life; sex; age

\section{Introduction}

The comorbidity of psychological disorders is a common problem that has serious implications for the delivery of health care. The lifetime prevalence of any disorder has been reported to be $46.4 \%$, while the lifetime prevalence of 2 and 3 disorders were found to be $27.7 \%$ and $17.3 \%$, respectively [1]. The 12-month prevalence of any disorder was found to be $26.2 \%$, while the 12-month prevalence of 2 and more disorders were reported to be $5.8 \%$ and $6 \%$, respectively, and over the same period, more than $40 \%$ of those with one diagnosis met the criteria for a second diagnosis [2].

Studies on comorbidity have found strong relationships between comorbidity and higher rates of suicide $[3,4]$, suicidal ideation [5], greater symptom severity [2,5], and poorer quality of life and social support [5]. Patients diagnosed with multiple disorders also tend to have a poorer prognosis, are less responsive to intervention, and generally exert a greater demand on the health care sector $[3,4,6]$.

Two approaches have been used to investigate comorbidity. The co-occurrence, or frequency approach, identifies individuals with a particular diagnosis and then counts how many of them meet the diagnostic criteria of another diagnosis. The resulting comorbidity proportions therefore depend on the reference group. For example, the proportion of people diagnosed with an anxiety disorder who also meet the diagnostic criteria for an eating disorder will be different than the proportion of people diagnosed with an eating disorder who also meet the criteria for that same anxiety disorder. Moreover, because there are more people diagnosed with anxiety disorders than people diagnosed with eating disorders, it is easier to have larger samples, and hence more accuracy, when the reference group is anxiety-disordered rather than eating-disordered. The second approach identifies the psychological disorders of a group of individuals, based on discrete or dimensional scales, and then uses factor analysis to identify clusters of disorders, hence the underlying structure or dimensions of comorbidity is addressed.

While comorbidity, and the structure of comorbidity using in-clinic samples, has been the focus of many investigations for several decades, investigating comorbidity using an online sample is relatively new. We are not aware of any study on comorbidity using individuals who received diagnoses based on online diagnostic tools. The e-PASS data of the Mental Health Online Platform (formerly Anxiety Online) (Figure 1) [7] provide us with a unique opportunity to investigate many facets of online therapy and assessment. We have recently reported on the structure of comorbidity of 21 psychological disorders, using online diagnostic assessment, based on severity dimensional scales [5]. In this paper, we present the frequencies of co-occurrences of 21 psychological disorders using an online assessment tool within a Web-based sample and relate the identified anxiety-depression clusters to suicidal ideation, social support, and quality of life.

The comorbidities of anxiety disorders with one another are common and have long been documented, and for some anxiety diagnoses, the lack of discriminant validly was criticized [5,8-13]. The presence of anxiety disorders in clinically depressed patients is most common [14] with at least $50 \%$ of all patients diagnosed with depression meeting the diagnostic criteria for at least one anxiety disorder [15-17] and $46 \%$ of those diagnosed with major depressive disorder (MDD) showing high levels of anxiety symptoms [18]. Estimates of anxiety disorders and MDD vary based on the age of and the target population under study. For example, the comorbidity of anxiety disorders and MDD in samples of children and adolescents ranges from $15.9 \%$ to $61.9 \%[19,20]$ and $14.5 \%$ to $57 \%$ in specific populations of adult samples [21,22]. Almeida-Filho et al [23] found $74 \%$ of the depressed sample reported symptoms of anxiety disorders and $61 \%$ of those with anxiety disorders were depressed. Feva et al [24] found 50.6\% of those diagnosed with MDD met the criteria for one or more anxiety disorders. Zimmerman et al [15] found $57.4 \%$ of 373 MDD outpatients meeting the criteria for at least one of the anxiety disorders. This finding was confirmed later by a meta-analysis study that concluded that $50 \%$ of individuals with MDD met the criteria for one or more anxiety disorders [25]. More specifically, Fava et al [18] found that $46 \%$ of MDD patients were significantly more likely to report symptoms associated with generalized anxiety disorder (GAD), obsessive-compulsive disorder (OCD), posttraumatic stress disorder (PTSD), agoraphobia without panic disorder (AwoPD), and panic disorder with or without agoraphobia (PD/A) than individuals without comorbid anxiety. In addition, $57 \%$ of the depressed outpatients with an anxiety disorder met the criteria for more than one anxiety disorder. In their sample, the most common comorbid anxiety disorders were social anxiety disorder (SAD) (33\%), specific phobia (SP) (13.7\%), PTSD (13.4\%), GAD (15\%), and PD/A (14.2\%) [15]. Furthermore, symptoms of insomnia and hypersomnia have also been consistently present with anxiety disorders and MDD [26-30].

Although research on the comorbidity of eating disorders with other psychological disorders has produced mixed and inconsistent results, there is sufficient empirical evidence supporting the co-occurrence of eating disorders with other disorders like anxiety disorders [31,32], MDD [31,33,34], body dysmorphic disorder (BDD) [35], and substance use (drugs and alcohol) [36,37]. The estimates of these comorbidities are generally moderate to high with a wide range. For example, $55 \%-98 \%$ of those diagnosed with anorexia nervosa meet the diagnostic criteria for another Axis I disorder [38,39]. 
MDD has been found to be prevalent in individuals diagnosed with eating disorders. Estimates of the lifetime prevalence of MDD range from 50\%-71\% in anorexia nervosa and 50\%-65\% in bulimia nervosa $[33,40,41]$. A more recent study by Jordan et al [34] reported $63 \%$ and $51 \%$ lifetime prevalence of major depression in a 56-female anorexia nervosa sample and a 132-female bulimia nervosa sample, aged 17-40 years, respectively. On the higher end, Blinder et al [38] reported that for a female sample aged 11-68 years, $92 \%$ of the 956 patients diagnosed with anorexia nervosa and $92 \%$ of the 882 patients diagnosed with bulimia nervosa had unipolar depression disorder, while Salbach-Andrae et al [42] reported that $60 \%$ of their adolescent girls aged 12-18 years exhibited comorbid mood disorder. Conversely, among women with MDD, the lifetime prevalence rate of anorexia nervosa was estimated at $1-7 \%$ and of bulimia nervosa at $9-21 \%[43,44]$.
Anxiety disorders are also prevalent in individuals diagnosed with eating disorders, although studies on anxiety disorders and eating disorders have produced mixed results $[32,45,46]$. Studies that used controlled groups reported significant comorbidities between anxiety disorders and eating disorders [32,47-50]. Depending on which one of the anxiety disorders is under investigation, estimates of the lifetime prevalence of anxiety disorders in eating disorders range from as low as $0 \%$ for specific phobia in anorexia nervosa [51] to as high as $79 \%$ for OCD in anorexia nervosa [52], and from as low as $2 \%$ for agoraphobia without panic disorder in bulimia nervosa [53] to as high as $59 \%$ for SAD in bulimia nervosa [54]. A summary of life prevalence rates of MDD and various anxiety disorders in anorexia nervosa and bulimia nervosa is shown in Table 1 $[33,34,38,47,51-59]$.

Table 1. Comorbidity of various anxiety disorders with anorexic nervosa and bulimia nervosa.

\begin{tabular}{|c|c|c|}
\hline Anxiety disorders/MDD & Lowest, \% [reference \#] & Highest, \% [reference \#] \\
\hline \multicolumn{3}{|l|}{ Anorexia nervosa } \\
\hline OCD & $14 \%[51]$ & $79 \%[52]$ \\
\hline SAD & $38 \%[47]$ & $55 \%[54]$ \\
\hline Agoraphobia without panic disorder & $3 \%[54]$ & $27 \%[47]$ \\
\hline Simple/Specific Phobia & $0 \%[51]$ & $45 \%[54]$ \\
\hline GAD & $24 \%[54]$ & $49 \%[47]$ \\
\hline $\mathrm{PD} / \mathrm{A}$ & $13 \%[47]$ & $43 \%[51]$ \\
\hline PTSD & $2 \%[47]$ & $7 \%[47]$ \\
\hline \multirow[t]{2}{*}{ MDD } & $46 \%[33]$ & $74 \%[33]$ \\
\hline & $63 \%[34]$ & $92 \%[38]$ \\
\hline \multicolumn{3}{|l|}{ Bulimia nervosa } \\
\hline OCD & $4 \%[53]$ & $43 \%[55]$ \\
\hline SAD & $30 \%[53]$ & $59 \%[54]$ \\
\hline Agoraphobia without panic disorder & $2 \%[53]$ & $35 \%[56]$ \\
\hline Simple/Specific Phobia & $3 \%[51]$ & $46 \%[57]$ \\
\hline GAD & $2 \%[53]$ & $55 \%[58]$ \\
\hline $\mathrm{PD} / \mathrm{A}$ & $10 \%[53]$ & $53 \%[51]$ \\
\hline PTSD & $5 \%[47]$ & $37 \%[59]$ \\
\hline \multirow[t]{2}{*}{ MDD } & $46 \%[33]$ & $74 \%[33]$ \\
\hline & $63 \%[34]$ & $92 \%[38]$ \\
\hline
\end{tabular}

It should be noted that the time of onset for anxiety disorders, MDD, and eating disorders are not the same. Some anxiety disorders are associated with early childhood onset while others are associated with onset during adolescence. However, Pallister and Waller [46] concluded that while the relative time of onset was inconsistent, females with eating disorders exhibited higher rates of anxiety disorders compared to controls, and suggested that eating disorders and anxiety disorders might have some common underlying factors.

Another disorder that seems to be present in eating disorders, particularly in anorexia nervosa, is BDD [35,60], coupled with features of OCD engaging in ritualistic-like behaviors to reduce anxiety generated by thoughts of one's poor self-image $[35,61,62]$.

Finally, the substance use by individuals with psychological disorders has long been investigated [36,63,64]. The rates of substance use disorders in patients diagnosed with mood disorders and anxiety disorders were reported to be $42 \%$ and $27 \%$, respectively [37].

In summary, the comorbidities of anxiety disorders, MDD, eating disorders, and substance use have long been established in clinical samples using traditional face-to-face assessment and diagnosis. Comorbidity estimates vary depending on the 
psychological disorder, age of the sample, and the specific population sample. There are no data available on the comorbidity of psychological disorders using online assessment and diagnostic tools with online samples.

The first purpose of this study is to report on the co-occurrences of 21 psychological disorders diagnosed in an online sample using an online assessment and diagnostic tool, e-PASS. While we will present the entire matrix of co-occurrences, we will focus on the comorbidities of anxiety disorders, major depressive episode (MDE), eating disorders, BDD, insomnia, hypersomnia, and alcohol use disorder. We will also report these comorbidities for males, females, separately, and together. The second purpose of this study is to examine the relationships between the identified anxiety-depression comorbidity clusters and three variables: suicidal ideation, social support, and quality of life.

Figure 1. Anxiety Online homepage image.

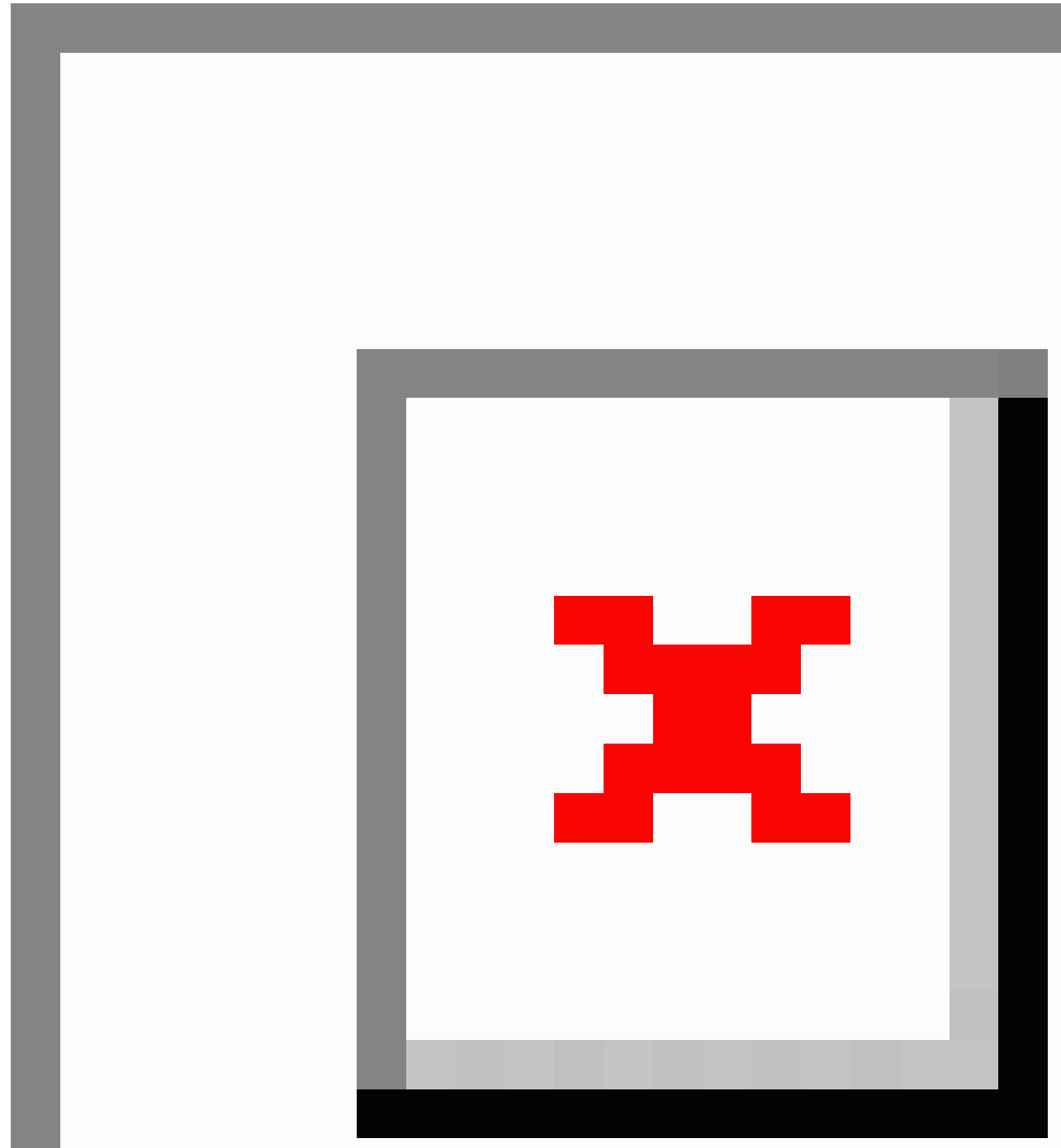

\section{Methods}

\section{Procedure}

The Mental Health Online platform consists of four centers, one of which is the assessment center containing the e-PASS (electronic psychological assessment screening system). The e-PASS includes a variety of demographic and personal questions and the Kessler- 6 and Suicidal Warnings measure, as well as the online diagnostic program. Individuals can access the Mental Health Online service from anywhere in the world provided they have an Internet connection. People can complete 
e-PASS if they are interested in the psychological assessment function and/or if they are interested in online treatment. Those who undertook the e-PASS were first required to register and consent to the Mental Health Online terms and conditions [7]. The procedures for collection and reporting of the Mental Health Online data were approved by the Swinburne University Human Research Ethics Committee.

\section{Diagnostic Assessment}

Based on an individual's response to some of the e-PASS questions, a person may be given a primary diagnosis and/or multiple secondary diagnoses. Primary or secondary diagnosis is determined by the reported presence of Diagnostic and Statistical Manual of Mental Disorders (4th edition, Text Revision) (DSM-IV-TR) symptoms and the average score on severity scales, each of which assesses the level of distress and interference caused by the symptoms of a particular disorder. A total of 21 clinical disorders are assessed by the e-PASS (see [5,65] for more details). The 21 psychological disorders and their abbreviations are shown in Multimedia Appendix 1.

The disorder specific severity score is the average of the scores on six questions that assess how distressed one is and how much the symptoms of a given disorder interfere in one's life (using a scale $0=$ no interference/distress to $8=$ severe interference/distress). A person who does not endorse enough of the initial DSM-IV-TR symptom criteria questions for a particular disorder is not presented with the questions assessing their level of distress and interference of those symptoms and is assigned a severity score of zero. Those who endorse the DSM-IV symptom criteria questions for a particular disorder are presented with the six distress and interference questions allowing the calculation of an averaged severity score ranging from 0-8. An averaged distress and interference severity score of 3.5 or above is considered sufficient to warrant a clinical diagnosis. Those whose average distress and interference severity scores are less than 3.5 are considered to warrant a subclinical (or subthreshold) diagnosis.

The e-PASS diagnostic system was informed by the Anxiety Disorders Interview Schedule (ADIS) clinician rating scale (a Likert scale from $0=$ no symptoms, to $4=$ mild presence of the disorder, to $8=$ very severe presence of the disorder). Most "total scores" would not be a whole number because the system used six rating scales and then averaged them. Thus, 4 is the typical score by a clinician using the ADIS that indicates the "presence" of a disorder. However, considering the decimal places resulting from the e-PASS averaging of the six rating scales, those scoring 3.5 and above were deemed clinical.

The psychometric properties of the e-PASS measures were shown to have high test-retest reliability and reasonable convergent validity with the structured clinical interviews (Nguyen, unpublished PhD thesis 2013). However, the small sample size and some disagreement with the structured clinical interviews in terms of the severity levels required for a clinical diagnosis, suggest that further validation studies with large sample sizes are needed.

For the purpose of this work, we will construct a frequency matrix representing the co-occurrences of all 21 psychological disorders diagnosed by the e-PASS system. We will identify the number of participants who met the criteria for a primary disorder (reference group) and then establish the proportion of the reference group who were given a secondary diagnosis for each of the remaining 21 disorders. We will also calculate these frequencies for males and females.

\section{Participants}

A total of 13,414 individuals completed the e-PASS phase between October 2009 and October 2012 and received at least one clinical diagnosis. The sample consisted of 3974 (29.6\%) males whose ages ranged between $18-85$ years old with a mean of 36.88 (SD 12.59) years, and $9440(70.4 \%)$ females whose ages ranged between 18-86 years old with a mean of 33.66 (SD 11.57) years. A total of 749 individuals received a clinical diagnosis (severity score greater than 3.5 ) of only one disorder, leaving 12,665 individuals who were classified as having a clinical or subclinical diagnosis for two or more of the 21 disorders assessed by e-PASS.

\section{Analysis}

The frequency of male and female participants who received a primary diagnosis on any particular disorder was first identified. Then, for each group, the frequencies of receiving secondary diagnoses for all 21 disorders were calculated. A series of hierarchical loglinear regression procedures were used to examine the relationships between anxiety-depression disorders and suicidal ideation, social support, and quality of life. For the significant comorbidity relationships with suicidal ideation, social support, and quality of life, demographic variables will also be explored.

\section{Results}

\section{Overview}

A frequency matrix of 21 -by-21 disorders is shown in Multimedia Appendix 2. The number of cases of males and females receiving a primary disorder is shown in column 3 for each disorder shown column 1. Columns 4 and onward in Multimedia Appendix 2 show the number of males, females, and total and their associated percentages of those receiving secondary diagnoses. For example, of the 858 males, 1761 females, and 2649 overall who received a primary diagnosis of MDE, there were 207 (24.13\%) males, 505 (28.68\%) females, and $712(26.88 \%)$ overall who received a secondary diagnosis of PD/A, respectively. Conversely, of the 478 males, 1000 females, and 1478 overall who received a primary diagnosis of PD/A, there were 289 (60.46\%) males, 615 (61.50\%) females, and $904(61.16 \%)$ overall who received a secondary diagnosis of MDE, respectively.

\section{Comorbidities of Primary Anxiety Disorders}

As shown in Multimedia Appendix 2, each anxiety disorder was comorbid with other anxiety disorders. GAD was the most comorbid anxiety disorder with other anxiety disorders ranging from 58.0\% (327/564) with specific phobia to $62.31 \%$ (921/1478) with PD/A. SAD was the second most comorbid anxiety disorder with other anxiety disorders ranging from $39.5 \%(183 / 463)$ with OCD to $65.1 \%$ (334/513) with 
agoraphobia without panic disorder. The third was specific phobia with a range from $31.6 \%$ (162/513) with agoraphobia without panic disorder to $44.25 \%(654 / 1478)$ with PD/A. The fourth was PD/A with a range from $28.25 \%$ (378/1338) with SAD to $41.0 \%(231 / 564)$ with specific phobia. The fifth was PTSD with a range from $20.7 \%$ (96/463) with OCD to $31.39 \%$ (464/1478) with PD/A. The sixth was OCD with a range from $8.95 \%(184 / 2056)$ with GAD to $34.9 \%$ (176/504) with PTSD The seventh was agoraphobia without panic disorder with a range from $13.8 \%$ (64/463) with OCD to $28.10 \%$ (376/1338) with SAD.

\section{Comorbidities of Depression, Anxiety Disorders, Insomnia/Hypersomnia, and Drug and Alcohol Abuse}

We first note that there were 858 males and 1761 females who received a primary diagnosis of MDE - a 2 to 1 female to male ratio. We also note the difference in comorbidity between males and females who have been diagnosed with MDE and one of the anxiety disorders. In all cases, except for OCD, the comorbidities of MDE with PD/A, agoraphobia without panic disorder, specific phobia, PTSD, GAD, and SAD among females are greater than the comorbidity among males. In addition, about $65.50 \%$ (1735/2649) of those diagnosed with MDE suffer from insomnia, whereas about $19.29 \%(511 / 2649)$ suffer from hypersomnia, with females reporting symptoms of insomnia and hypersomnia in greater numbers. Also, 21.10\% (559/2649) of those diagnosed with MDE report alcohol abuse with males reporting alcohol use in greater numbers.

On average, we found $58.38 \%$ of those receiving a primary diagnosis of one of the anxiety disorders also received a secondary diagnosis of MDE. Conversely, on average, we found approximately $35 \%$ of those who received a primary diagnosis of MDE also received a secondary diagnosis of one or more anxiety disorders. The lowest comorbidity was between MDE and agoraphobia without panic disorder at about $17.93 \%$ (475/2649), whereas the highest comorbidity was between MDE and GAD at about $59.61 \%$ (1579/2649). The remaining anxiety disorders in order of frequency magnitude were OCD (710/26.80\%), PD/A (712/2649, 26.88\%), specific phobia
$(803 / 2649,30.31 \%)$, PTSD $(883 / 2649,33.33 \%)$, and SAD $(1336 / 2649,50.43 \%)$.

Results show the presence of the following substance dependency in participants who received a primary diagnosis of MDE: cannabis (202/2649, 7.63\%), stimulant (114/2649, $4.3 \%)$, opioid $(71 / 2649,2.68 \%)$, sedative $(252 / 2649,9.51 \%)$, and alcohol $(559 / 2649,21.10 \%)$. Most significant was the difference between depressed males and females in alcohol dependence $(25.76 \%$ (221/858) for males vs $19.19 \%$ (338/1761) for females).

The highest percentage of substance dependency present in all anxiety disorders diagnosed by e-PASS was found for males with GAD and alcohol dependence at $24.06 \%$ (141/586), for females with specific phobia and alcohol dependence at $15.10 \%$ (61/404), and for both males and females with GAD and alcohol dependence at $17.41 \%(358 / 2056)$.

Results indicate insomnia was present in all disorders ranging from $41.25 \%$ to $83.67 \%$ for the combined male/female samples. For males, the co-occurrence of insomnia was found highest with somatization disorder at $100 \%$ and lowest with opioid dependency and OCD at $33.33 \%$ and $33.71 \%$, respectively. For females, the co-occurrence of insomnia was found highest with somatization disorder at $80.0 \%(32 / 40)$ and lowest with alcohol dependency at $42.1 \%(40 / 95)$.

\section{Comorbidities of Eating Disorders With Anxiety and Major Depressive Disorders}

There were a total of 14 participants ( 3 males and 11 females) diagnosed with anorexia nervosa, whereas 505 participants (26 males and 479 females) diagnosed with bulimia nervosa. Results showed that $71.43 \%$ (0\% males vs $90.91 \%$ females) and $71.68 \%$ ( $80.77 \%$ males vs $71.19 \%$ females) of those receiving a primary diagnosis of anorexia nervosa and bulimia nervosa, respectively, also received a secondary diagnosis of MDE. The co-occurrences of primary diagnosis of anorexia nervosa or bulimia nervosa with the presence of a secondary diagnosis of 1 of 7 anxiety disorders for males, females, and the total sample are extracted from Multimedia Appendix 2 and are shown in Table 2.

Table 2. Comorbidities of anxiety disorders, MDE in anorexia nervosa and bulimia nervosa groups.

\begin{tabular}{|c|c|c|c|c|c|c|}
\hline \multirow[t]{2}{*}{ Anxiety disorders } & \multicolumn{3}{|c|}{ Anorexia nervosa, n (\%) } & \multicolumn{3}{|c|}{ Bulimia nervosa, n (\%) } \\
\hline & Male $(n=3)$ & Female $(n=11)$ & Total $(\mathrm{N}=14)$ & Male $(n=26)$ & Female $(n=479)$ & Total $(\mathrm{N}=505)$ \\
\hline OCD & $1(33.3)$ & $5(45.5)$ & $6(42.9)$ & $12(46.2)$ & $171(35.7)$ & $183(36.2)$ \\
\hline SAD & $1(33.3)$ & 7 (63.6) & $8(57.1)$ & $13(50.0)$ & 239 (49.9) & $252(49.9)$ \\
\hline GAD & $1(33.3)$ & $8(72.7)$ & $9(64.3)$ & $15(57.7)$ & $248(51.8)$ & $263(52.1)$ \\
\hline PTSD & $1(33.3)$ & $2(18.2)$ & $3(21.4)$ & $7(26.9)$ & $160(33.4)$ & $167(33.1)$ \\
\hline SP & $0(0.0)$ & $4(36.4)$ & $4(28.6)$ & $9(34.6)$ & $127(26.5)$ & $136(26.9)$ \\
\hline AwoPD & $1(33.3)$ & $1(9.1)$ & $2(14.3)$ & 7 (26.9) & $64(13.4)$ & $71(14.1)$ \\
\hline
\end{tabular}

As shown in Table 2, the comorbidity rate of anorexia nervosa with any of the 7 anxiety disorders was highest for females diagnosed with GAD at $72.7 \%$ and lowest for females diagnosed with agoraphobia without panic disorder at $9.1 \%$. Similarly, the comorbidity rate of bulimia nervosa with any of the 7 anxiety disorders was highest for females diagnosed with GAD at $51.8 \%$ and lowest for females diagnosed with PD/A at $26.3 \%$. 
It should be noted that the rate of comorbidity depends on the reference group. For example, as shown in Multimedia Appendix 2, the rate of co-occurrence of MDE in the bulimia nervosa group was $80.8 \%$ (21/26) for males, $71.2 \%$ (341/479) for females, and $71.7 \%(362 / 505)$ for both. However, the rate of co-occurrence of bulimia nervosa in the MDE group was found to be $4.6 \%$ (39/858) for males, $14.82 \%$ (261/1761) for females, and $11.33 \%(300 / 2649)$ for both, and the rate of co-occurrence of anorexia nervosa in the MDE group was found to be $0 \%$ for males, $1 \%$ for females, and $1 \%$ for both.

\section{Relationships Between Comorbidities of Anxiety and Depressive Disorders and Psychosocial Variables}

The data contained 6 anxiety disorders with the following primary diagnoses frequencies: $\operatorname{GAD}(n=2056), \mathrm{PD} / \mathrm{A}(\mathrm{n}=1478)$, SAD $(n=1338)$, specific phobia $(n=564)$, PTSD $(n=504)$, and OCD $(n=463)$. The data also contained 2649 participants who received a primary diagnosis of MDE. Cross-tabulation of these 7 disorders resulted in cells with fewer than 5 participants. To maintain a cell count of 5 or greater, specific phobia, PTSD, and OCD were removed from further analyses. For the next several hierarchical loglinear analyses, MDE, GAD, PD/A, and SAD were used with each of the following variables: suicidal ideation, social support, and quality of life. In addition, age was split into young (those between 18 and 35 years old) and older (those over 35 years old). Sex of participants was also split into males and females.

\section{Anxiety, Depression, and Suicidal Ideation}

Three anxiety disorders (PD/A, SAD, GAD) and MDE with suicidal ideation were entered into a hierarchical loglinear regression. The 5-way loglinear analyses resulted in a model with a non-significant likelihood ratio $\left(\chi_{10}^{2}=9.6, P=.476\right)$ that retained 3-way effects $\left(\chi_{16}^{2}=97.7, P<.001\right)$. Results of the backward elimination showed 2 significant triads that contained suicidal ideation: $\mathrm{PD} / \mathrm{A} * \mathrm{SAD} *$ suicidal ideation and $\mathrm{PD} / \mathrm{A} * \mathrm{MDE} *$ suicidal ideation. Two new hierarchical loglinear models were constructed. The first model was based on PD/A, $\mathrm{SAD}$, suicidal ideation, age, and sex that resulted in a non-significant likelihood ratio $\left(\chi_{10}^{2}=12.7, P=.240\right)$ that retained 3 -way effects $\left(\chi_{16}^{2}=81.5, P<.001\right)$. The second model was based on PD/A, MDE, suicidal ideation, age, and sex which resulted in a non-significant likelihood ratio $\left(\chi^{2}{ }_{10}=6.5, P=.772\right)$ that retained 3-way effects $\left(\chi_{16}^{2}=34.8, P=.004\right)$. Consequently, a new model with PD/A, SAD, MDE, suicidal ideation, age, and sex with only 3-way effects resulted in a non-significant likelihood ratio $\left(\chi_{32}^{2}=22.4, P=.90\right)$. Backward elimination resulted in 2 significant triads that included suicidal ideation, MDE-PD/A comorbidity dyad and PD/A-SAD comorbidity dyad, as shown in Table 3. A $2 \times 2$ cross-tabulation for those who reported no suicidal ideation and for those who reported suicidal ideation was performed separately for the MDE-PD/A comorbidity dyad and for the PD/A-SAD comorbidity dyad.

Table 3. Values and significance of chi square test for 3-way interactional terms for MDE, PD/A, SAD, sex, and age with suicidal ideation.

\begin{tabular}{lll}
\hline 3-way interaction & $\chi^{2}(\mathrm{df}=1)$ & $P$ \\
\hline MDE*PD/A*SAD & 13.7 & .000 \\
MDE*PD/A*suicidal ideation & 7.6 & .006 \\
MDE*SAD*Sex & 8.3 & .004 \\
PD/A*SAD*Suicidal ideation & 14.3 & .000 \\
PD*SAD*Age & 22.7 & .000 \\
Suicidal Ideation*Sex*Age & 6.0 & .014 \\
\hline
\end{tabular}

\section{MDE-PD/A Comorbidity Dyad}

For the non-suicidal ideation group, there was a significant association between MDE and whether or not PD/A was endorsed $\left(\chi_{1}^{2}=11.1, P=.001\right)$. The odds for the non-suicidal ideation group endorsing both MDE and PD/A were 1.18 times higher than if they had endorsed MDE only. For the suicidal ideation group, there was a significant association between
MDE and whether or not PD/A was endorsed $\left(\chi_{1}^{2}=21.0\right.$, $P<.001)$. This was based on the finding that the odds of the suicidal ideation group endorsing both MDE and PD/A were 1.84 times higher than if they had endorsed MDE only. The frequencies of all combinations of PD/A, MDE, sex, and age of those who reported suicidal ideation are shown in Table 4, and a graph illustrating the effect of sex and age on suicidal ideation when there is PD/A and MDE comorbidity is shown in Figure 2. 
Table 4. Frequencies (\%) of those endorsing suicidal ideation by PD/A*MDE*Sex*Age.

\begin{tabular}{lllll}
\hline PD/A & MDE & Sex & Age & Suicidal ideation, n/N (\%) \\
\hline Yes & Yes & M & Y ( $\leq 35)$ & $309 / 547(56.5)$ \\
Yes & Yes & M & O (>35) & $266 / 449(59.2)$ \\
Yes & Yes & F & Y & $1075 / 1757(61.18)$ \\
Yes & Yes & F & O & $416 / 809(51.4)$ \\
Yes & No & M & Y & $15 / 183(8.2)$ \\
Yes & No & M & O & $12 / 170(7.1)$ \\
Yes & No & F & Y & $40 / 550(7.3)$ \\
Yes & No & F & O & $18 / 314(5.7)$ \\
No & Yes & M & Y & $455 / 908(50.1)$ \\
No & Yes & M & O & $416 / 883(47.1)$ \\
No & Yes & F & Y & $1194 / 2419(49.36)$ \\
No & Yes & F & O & $676 / 1547(43.70)$ \\
\hline
\end{tabular}

Figure 2. Sex by age for those who endorsed suicidal ideation (\% frequency) and endorsed PD/A and MDE.

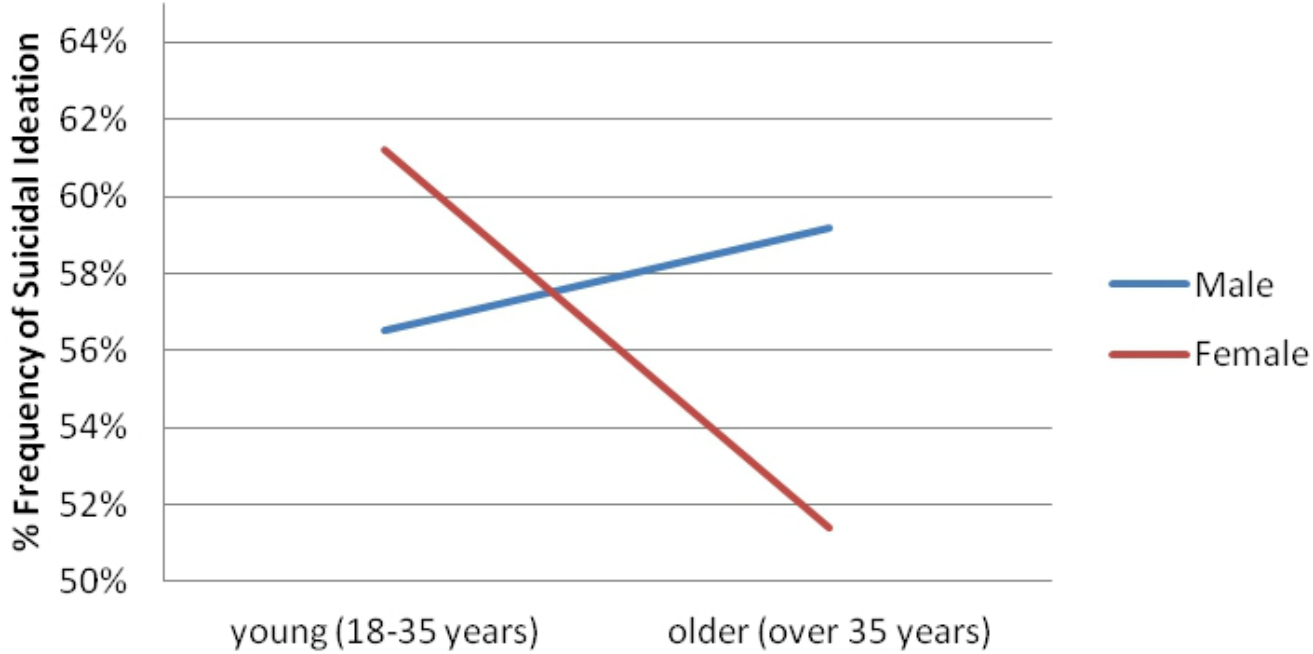

\section{PD/A-SAD Comorbidity Dyad}

For the non-suicidal ideation group, there was a significant association between $\mathrm{PD} / \mathrm{A}$ and whether or not SAD was endorsed $\left(\chi_{1}^{2}=34.6, P<.001\right)$. The odds of the non-suicidal ideation group endorsing both $\mathrm{PD} / \mathrm{A}$ and $\mathrm{SAD}$ were 1.32 times higher than if they had endorsed PD/A only. For the suicidal ideation group, there was a significant association between
$\mathrm{PD} / \mathrm{A}$ and whether or not SAD was endorsed by this group $\left(\chi_{1}^{2}=140.4, P<.001\right)$. The odds of the suicidal ideation group endorsing both PD/A and SAD were 2.07 times higher than if they had endorsed PD/A only. The frequencies of all combinations of PD/A, SAD, sex, and age of those who reported suicidal ideation are shown in Table 5, and a graph of the effect of age and sex on suicidal ideation in the presence of a PD/A and SAD comorbidity is shown in Figure 3. 
Table 5. Frequencies (\%) of those endorsing suicidal ideation by PD/A*SAD*Sex*Age.

\begin{tabular}{lllll}
\hline PD/A & SAD & Sex & Age & Suicidal ideation, n/N (\%) \\
\hline yes & yes & M & Y $(\leq 35)$ & $244 / 479(50.9)$ \\
yes & yes & M & O ( >35) & $197 / 392(50.28)$ \\
yes & yes & F & Y & $842 / 1496(56.3)$ \\
yes & yes & F & O & $314 / 689(45.6)$ \\
yes & no & M & Y & $80 / 251(31.9)$ \\
yes & no & M & O & $81 / 227(35.7)$ \\
yes & no & F & Y & $273 / 811(33.7)$ \\
yes & no & F & O & $120 / 434(27.6)$ \\
no & yes & M & Y & $303 / 776(39)$ \\
no & yes & M & O & $247 / 633(39)$ \\
no & yes & F & Y & $804 / 2021(39.78)$ \\
no & yes & F & O & $361 / 1049(34.41)$ \\
\hline
\end{tabular}

Figure 3. Sex by age for those who endorsed suicidal ideation (\% frequency) and endorsed PD/A and SAD.

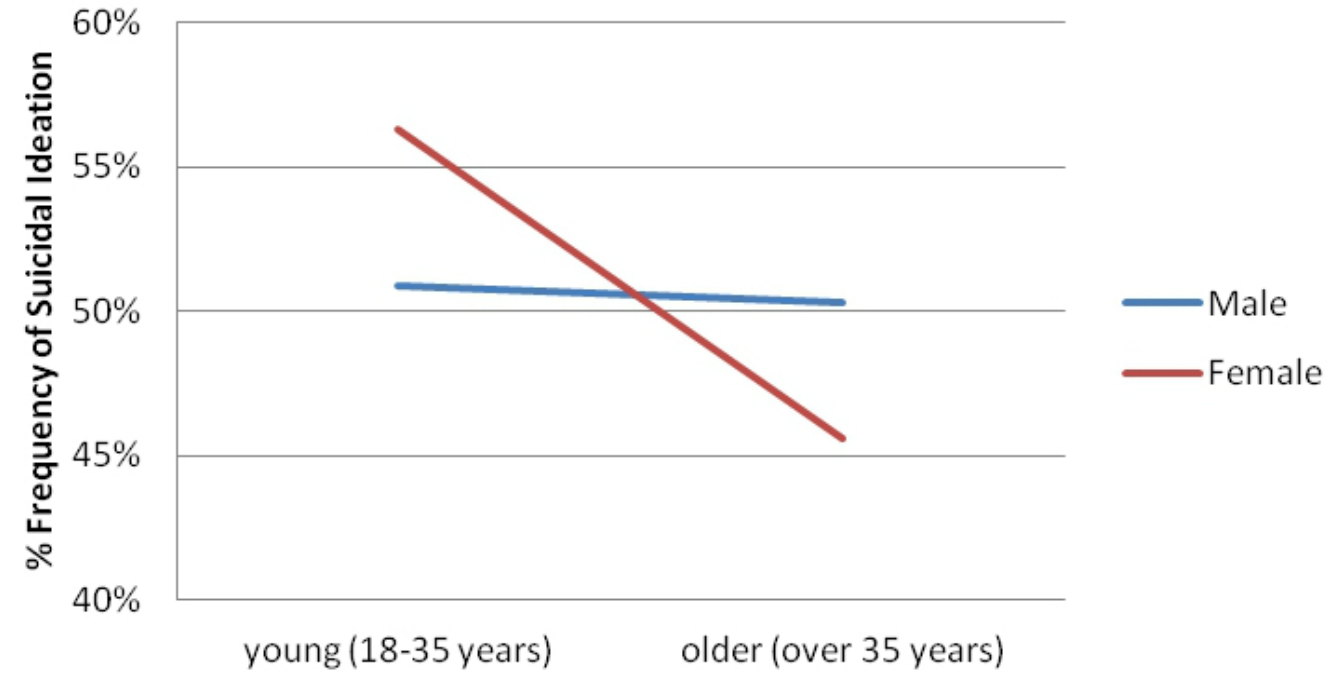

\section{Anxiety, Depression, and Social Support}

Three anxiety disorders (PD/A, SAD, GAD) and MDE with social support were entered into a hierarchical loglinear regression. The 5-way loglinear resulted in a model, with a non-significant likelihood ratio $\left(\chi_{10}^{2}=7.1, P=.72\right)$, which retained 3 -way effects $\left(\chi_{16}^{2}=86.5, P<.001\right)$. Results of the backward elimination showed 1 significant triad that contained social support, $\mathrm{PD} / \mathrm{A} * \mathrm{GAD} *$ social support $\left(\chi^{2}{ }_{1}=4.3, P=.038\right)$. The remaining 4 significant triads were the 3 -way interactions of
MDE*GAD*PD/A, MDE*GAD*SAD, GAD*PD/A*SAD, and $\mathrm{MDE} * \mathrm{PD} / \mathrm{A} * \mathrm{SAD}$ that did not include social support. A hierarchical loglinear model was constructed using PD/A, GAD, and social support with sex and age. The resulting model had a non-significant likelihood ratio $\left(\chi_{10}^{2}=2.2, P=.994\right)$ that retained 3 -way effects $\left(\chi_{16}^{2}=40.4, P=.001\right)$. A new model with only 3 -way effects resulted in a non-significant likelihood ratio $\left(\chi_{16}^{2}=17.7, P=.35\right)$. Backward elimination resulted in one significant triad that included social support and GAD-PD/A comorbidity dyad, as shown in Table 6.

Table 6. Values and significance of chi square test for 3-way interactional terms for GAD, PD/A, sex, and age with social support.

\begin{tabular}{lll}
\hline 3-way interaction & $\chi^{2}(\mathrm{df}=1)$ & $P$ \\
\hline GAD*PD/A*Social Support & 9.6 & .002 \\
GAD*Sex*Age & 19.6 & .000 \\
PD*Age & 42.5 & .000 \\
Social Support*Sex & 14.9 & .000 \\
\hline
\end{tabular}


A $2 \times 2$ cross-tabulation for those who reported inadequate social support and for those who reported adequate social support was performed separately for the GAD-PD/A comorbidity dyad. For those who reported inadequate social support, there was a significant association between GAD and whether or not PD/A was endorsed $\left(\chi_{1}^{2}=119.12, P<.001\right)$. This was based on the finding that the odds of inadequate social support group endorsing both GAD and PD/A were 1.84 times higher than if they had endorsed GAD only. For those who reported adequate social support, there was a significant association between GAD and whether or not PD/A was endorsed $\left(\chi^{2}{ }_{1}=40.31, P<.001\right)$. The odds of the adequate social support group endorsing both $\mathrm{GAD}$ and $\mathrm{PD} / \mathrm{A}$ were 1.42 times higher than if they had endorsed GAD only. Table 7 shows the frequencies of all combinations of PD/A, GAD, sex, and age of those who endorsed adequate social support.

Table 7. Frequencies (\%) of those endorsing social support by PD/A*GAD*Sex*Age.

\begin{tabular}{lllll}
\hline PD/A & GAD & Sex & Age & Social support, n/N $(\%)$ \\
\hline Yes & Yes & M & Y $(\leq 35)$ & $189 / 507(37.3)$ \\
Yes & Yes & M & O $(>35)$ & $166 / 435(38.2)$ \\
Yes & Yes & F & Y & $671 / 1744(38.47)$ \\
Yes & Yes & F & O & $304 / 793(38.3)$ \\
Yes & No & M & Y & $116 / 223(52.0)$ \\
Yes & No & M & O & $97 / 184(52.7)$ \\
Yes & No & F & Y & $294 / 563(52.2)$ \\
Yes & No & F & O & $193 / 330(58.5)$ \\
No & Yes & Y & $301 / 781(38.5)$ \\
No & Yes & M & O & $306 / 787(38.9)$ \\
No & Yes & F & Y & $1032 / 2362(43.69)$ \\
No & Yes & F & O & $639 / 1421(44.97)$ \\
\hline
\end{tabular}

\section{Anxiety, Depression, and Quality of Life}

Three anxiety disorders (PD/A, SAD, GAD) and MDE with quality of life were entered into a hierarchical loglinear regression. The 5-way loglinear resulted in a model, with a non-significant likelihood ratio $\left(\chi_{10}^{2}=11.1, P=.35\right)$ that retained 3 -way effects $\left(\chi_{16}^{2}=92.6, P<.001\right)$. Results of the backward elimination showed 1 significant triad that contained quality of life, $\mathrm{PD} / \mathrm{A} * \mathrm{SAD} *$ quality of life $\left(\chi_{1}^{2}=4.6, P=.031\right)$. The remaining 3 significant triads were the 3-way interactions of $\mathrm{MDE} * \mathrm{PD} / \mathrm{A} * \mathrm{SAD}, \mathrm{MDE} * \mathrm{GAD} * \mathrm{SAD}$, and $\mathrm{MDE} * \mathrm{GAD} * \mathrm{PD} / \mathrm{A}$ that did not include quality of life. A hierarchical loglinear model was constructed using PD/A, SAD, and quality of life with sex and age. The resulting model had a non-significant likelihood ratio $\left(\chi_{10}^{2}=7.7, P=.66\right)$ that retained 3-way effects $\left(\chi_{16}^{2}=56.0, P<.001\right)$. A new model with only 3-way effects resulted in a non-significant likelihood ratio $\left(\chi_{13}^{2}=14.1, P=.37\right)$. Backward elimination resulted in one significant triad that included quality of life and PD/A-SAD comorbidity dyad. The rest of the 5 significant triads did not include any comorbidity dyad with the quality of life term, as shown in Table 8 .

Table 8. Values and significance of chi square test for 3-way interactional terms for SAD, PD/A, sex, and age with quality of life.

\begin{tabular}{lll}
\hline 3-way interaction & $\chi^{2}(\mathrm{df}=1)$ & $P$ \\
\hline PD*Quality of Life*SAD & 16.4 & .000 \\
PD*Quality of Life*Sex & 4.1 & .042 \\
PD*SAD*Age & 18.0 & .000 \\
PD*Sex*Age & 4.2 & .040 \\
SAD*Sex & 5.4 & .020 \\
\hline
\end{tabular}

A $2 \times 2$ cross-tabulation for those who reported poor quality of life and for those who reported good quality of life was performed separately for PD/A-SAD comorbidity dyad. For those who reported poor quality of life, there was a significant association between PD/A and whether or not SAD was endorsed $\left(\chi_{1}^{2}=130.1, P<.001\right)$. This was based on the finding that the odds of poor quality of life group endorsing both PD/A and SAD were 1.87 times higher than if they had endorsed PD/A only. For those who reported good quality of life, there was a significant association between PD/A and whether or not SAD was endorsed by this group $\left(\chi_{1}^{2}=34.3, P<.001\right)$. The odds of the good quality of life group endorsing both PD/A and SAD were 1.35 times higher than if they had endorsed PD/A only. The frequencies of all combinations of PD/A, SAD, sex, and 
age of those who endorsed good quality of life are shown in Table 9.

Table 9. Frequencies (\%) of those endorsing quality of life by PD/A, SAD, sex, and age.

\begin{tabular}{lllll}
\hline PD/A & SAD & Sex & Age & Quality of life, n/N $(\%)$ \\
\hline Yes & Yes & M & Y $(\leq 35)$ & $188 / 479(39.2)$ \\
Yes & Yes & M & O (>35) & $145 / 392(37.0)$ \\
Yes & Yes & F & Y & $567 / 1496(37.90)$ \\
Yes & Yes & F & O & $270 / 689(39.2)$ \\
Yes & No & M & Y & $147 / 251(58.6)$ \\
Yes & No & M & O & $113 / 227(54.4)$ \\
Yes & No & F & Y & $503 / 811(62.0)$ \\
Yes & No & F & O & $253 / 434(58.3)$ \\
No & Yes & M & Y & $339 / 776(43.7)$ \\
No & Yes & M & O & $386 / 663(45.2)$ \\
No & Yes & F & Y & $1011 / 2021(50.02)$ \\
No & Yes & F & O & $519 / 1049(49.48)$ \\
\hline
\end{tabular}

\section{Discussion}

\section{Principal Findings}

A frequency matrix of the co-occurrence of 21 psychological disorders based on primary and secondary diagnoses of 12,665 individuals who were assessed using the e-PASS online diagnostic system was constructed. To the best of our knowledge, such a matrix for this many psychological disorders has not been presented before for traditional in-clinic diagnosis or for any online diagnostic tools. As such, comparisons with existing literature should be viewed with caution. We present this matrix to serve as a preliminary and potentially useful reference for future works in the area of online assessment and diagnosis.

Given the high number of disorders in the matrix and limited discussion space, we will focus on a few disorders that are of most interest and/or have been studied before in in-clinic samples.

\section{Depression, Anxiety Disorders, Insomnia/Hypersomnia, and Drug and Alcohol Abuse}

One area that has been studied extensively is the comorbidity of MDE and the various anxiety disorders, and alcohol abuse. We found the number of females receiving a primary diagnosis of MDE was twice the number of males receiving a primary diagnosis of MDE. This ratio of about 2:1 females to males is consistent with in-clinic samples and face-to-face diagnostic tools. We also found the comorbidities of MDE with all anxiety disorders, except for OCD, among females to be greater than the same comorbidities among males. In addition, the majority (2 in 3) of those diagnosed with MDE reported insomnia, whereas 1 in 5 reported hypersomnia, with greater numbers of females than males reporting symptoms of insomnia and hypersomnia. Moreover, 1 in 5 of those diagnosed with MDE reported alcohol abuse with greater numbers of males than females reporting alcohol abuse.
On average, we found approximately 1 in 3 of those who received a primary diagnosis of MDE also received a secondary diagnosis of one or more anxiety disorders. The lowest comorbidity was found between MDE and agoraphobia without panic disorder whereas the highest comorbidity was between MDE and GAD. These results are consisted with findings based on in-clinic samples $[15,21,24,25,66]$. Our findings are also consistent with Fava et al [24] who found that $46 \%$ of MDD patients were significantly more likely to report symptoms associated with GAD, OCD, PTSD, agoraphobia without panic disorder, and $\mathrm{PD} / \mathrm{A}$ than individuals without comorbid anxiety. On the higher end, Almeida-Filho et al [23] found 74\% of a depressed Brazilian sample reported symptoms of anxiety disorders, which is much higher than our results of 35\%. This discrepancy is possibly due to the fact that they used reported symptoms of anxiety disorders, whereas this study used adherence to the DSM-IV-TR diagnostic criteria. On the other hand, our result that almost 2 in 3 of those receiving a primary diagnosis of one of the anxiety disorders was also receiving a secondary diagnosis of MDE is consistent with Almeida-Filho et al's [23] results that $61 \%$ of those with anxiety disorders were depressed.

We also found high rates of comorbidities among anxiety disorders with GAD being the most comorbid anxiety disorder with other anxiety disorders followed by SAD, specific phobia, PD/A, PTSD, OCD, and agoraphobia without panic disorder. These results are consistent with previous research findings that found anxiety disorders to have high comorbidities with each other and that questioned the discriminant validity of some anxiety diagnoses such as GAD [5,8-13]. This consistency may suggest that there are no differences between online and in-clinic assessment systems and online and in-clinic populations.

The comorbidities between MDE and various substance dependency (ranging between 3\% to $21 \%$ ) found in this study are much lower than the $42 \%$ of mood disordered patients who had substance use disorders as reported by McGovern et al [37]. 
Again, this discrepancy may be due to this study's strict adherence to the diagnostic criteria.

The highest comorbidity of substance dependency present in all anxiety disorders was found for males who received a primary diagnosis of GAD and a secondary diagnosis of alcohol dependence at $24.06 \%$, and for females who received a primary diagnosis of specific phobia and a secondary diagnosis of alcohol dependence at $15.10 \%$. McGovern et al [37], without examining males and females separately, found substance use disorders present in $27 \%$ of patients diagnosed with anxiety disorders, which is, again, slightly greater than results of this study of about $17 \%$ for the combined male and female samples. Almeida-Filho et al [23] found 20\% of cases of alcoholism co-occurring with anxiety disorders and MDD diagnoses.

This study also found insomnia to be present in all disorders ranging from $41.25 \%$ to $83.67 \%$ for the combined male/female samples across all disorders. This association between insomnia and psychological disorders is consistent with the literature. For example, the presence of sleep problems has been consistently found in patients with anxiety and mood disorders [5,26-30].

\section{Eating Disorders, Anxiety Disorders, and Major Depression}

The interpretation of the comorbidities of anorexia nervosa with other disorders should be viewed with caution because of the small number of participants who were diagnosed with anorexia nervosa. Overall, our results are consistent with the previously found rates of anorexia nervosa and bulimia nervosa comorbidities with MDE and anxiety disorders. Specifically, we found $71.43 \%$ and $71.68 \%$ of those receiving a primary diagnosis of anorexia nervosa and bulimia nervosa, respectively, also received a secondary diagnosis of MDE. The comorbidity of anorexia nervosa and MDE found in this study is within the range of $50 \%-71 \%$ reported by previous studies [33,34,40-42]. However, the result for the comorbidity of bulimia nervosa and MDE found in this study is slightly greater than the range of $50 \%-65 \%$ reported by previous investigations $[33,34,40,41]$.

The rates of co-occurrence of bulimia nervosa and anorexia nervosa in the MDE group found in this study are consistent with the estimated lifetime prevalence of anorexia nervosa in MDD (1\%-7\%) and of bulimia nervosa in MDD (9\%-21\%) reported by Carter et al [43] and Fava et al [44]. It is expected that a larger proportion of bulimia nervosa individuals experience symptoms of depression while a much smaller percentage of depressed individuals experience symptoms of bulimia nervosa.

While the choice of the reference group is very important in establishing comorbidity rates, it varies in importance. For example, while defining the reference group in the case of MDE or anxiety disorders and bulimia nervosa or anorexia nervosa is important, it is less so when defining the reference group for MDE and GAD. As shown in Multimedia Appendix 2, the co-occurrence of MDE in the GAD group is $66.83 \%$ whereas the co-occurrence of GAD in the MDE group is $59.61 \%$ for combined male and female sample.

For the most part, results of this study are consistent with previous findings. However, results do not fall within the range found in previous studies on three occasions. The comorbidity rate for anorexia nervosa with GAD $(64 \%)$ found by this study is outside the range of $24 \%-49 \%$ reported by Godart et al $[47,54]$. Similarly the comorbidity rate for anorexia nervosa with PTSD $(21 \%)$ is outside the range of $2 \%-7 \%$ given by Godart et al [47]. In both cases, the results of this study are based on very few participants with anorexia nervosa and therefore should be interpreted with caution. Finally, the comorbidity rate for bulimia nervosa with MDE (72\%) is slightly outside the range of $61 \%-65 \%$ reported by Jordan et al [34] and Casper [33].

This study also examined the interactional relationships between GAD, SAD, PD/A, MDE, sex, and age and three variables: suicidal ideation, social support, and quality of life using a series of hierarchical loglinear analyses. In each case, 3-way interaction effects were found. For suicidal ideation, the odds of endorsing having suicidal ideation was greater for those diagnosed with depression and PD/A than depression only, and for those diagnosed with PD/A and SAD than PD/A only. These results suggest that comorbidity, even for two disorders, increases the risk of having suicidal thoughts, as indicated by previous research [3-5]. We also found a significant interactional effect for sex by age. The frequency of younger females (18-35 years old) diagnosed with MDE and PD/A or PD/A and SAD endorsing suicidal ideation was about $10 \%$ greater than older females (over 35 years old) and about 5\% greater than their counterpart younger or older males. These results suggest that younger females who have these comorbidity dyads are at greater risk of having suicidal ideation.

The results of this study found the GAD and PD/A dyad to be the only one to have a significant relationship with social support. The odds for reporting having inadequate social support was greater for those diagnosed with GAD and PD/A than GAD only. There are not many studies that examined the relationship between comorbidity and social support, but one recent study reported a negative relationship between comorbidity and social support [5]. We should note here that this study found no significant interactional effect between GAD and PD/A comorbidity dyad and sex, age, and social support. These results suggest that sex and age have little effect on the relationship between this dyadic comorbidity and social support.

Finally, the results suggested that the PD/A and SAD dyad was the only dyad to have a significant relationship with quality of life. The odds for reporting having a poor quality of life was greater for those diagnosed with PD/A and SAD than PD/A only. Again, only one study reported a negative relationship between comorbidity and quality of life [5]. Also, as was the case with social support, we found no significant interactional effect between the PD/A-SAD comorbidity dyad and sex, age, and quality of life. These results suggest that sex and age have no effect on the relationship between this dyadic comorbidity and quality of life.

\section{Transdiagnostic Approaches}

There is growing support for using transdiagnostic approaches for the assessment and treatment of psychological disorders. AL-Asadi et al [5] using dimensional scales found overlapping dimensions underlying the various psychological disorders. 
Moses and Barlow [67] and Barlow et al [68] concluded that at a minimum, a diagnostic specific approach and transdiagnostic approaches to treatments are equally effective. AL-Asadi et al [69] found significant reduction in the severity of symptoms of depression as a result of participants receiving anxiety-specific treatment and supported the efficacy of online therapy to provide transdiagnostic treatment. McEvoy et al's [70] review of the literature concluded that transdiagnostic treatments were associated with improvements in comorbidity disorders and with high client satisfaction, therapeutic alliance, group cohesion, and positive treatment expectations. McManus et al [71] pointed out the potential of transdiagnostic approaches in addressing multiple comorbid anxiety disorders. Wade et al [72] found support for using transdiagnostic approaches to understanding eating disorders. Results of this study provide further support for the use of transdiagnostic approaches to the assessment and treatment of psychological disorders.

\section{Limitations}

One of the major limitations of this study is the lack of a control group. The online system does not require the inclusion of a control group and consequently any conclusion must be taken as preliminary. Another limitation is the lack of research on the sensitivity and the psychometric properties of the e-PASS system. There is only one unpublished study that found the e-PASS system to have high test-retest reliability and adequate convergent validity (Nguyen, unpublished PhD thesis, 2013). Unfortunately, even this one study has used a small sample size and found disagreement between e-PASS and structured clinical interviews when it came to the level of severity required for a clinical diagnosis. More validation studies with larger samples and using the newly released DSM- 5 criteria are required before definitive conclusions can be made. The last limitation is inherent to all self-report instruments such as e-PASS. The exclusive reliance of e-PASS on automated online self-report measures brings into question the extent to which diagnosing individuals is reliable. Concerns have been raised regarding the reliability of online diagnostic tools [73].

\section{Conclusions}

In summary, overlap between psychological disorders for our online sample using the online assessment tool, e-PASS, was confirmed and was found to be similar to in-clinic samples using face-to-face assessment tools. Overall, there did not appear to be much difference in the rates of comorbidities of psychological disorders between in-clinic samples using face-to-face assessment and diagnostic tools and our online sample using the online assessment and diagnostic tool, e-PASS. The results of this study showed that the comorbidity rates for the online sample using e-PASS commonly fell within the range found for in-clinic samples using in-clinic assessment tools. The observation that e-PASS and face-to-face assessment tools generally yielded the same result may provide further evidence to the validity and the utility of the Anxiety Online Platform and the e-PASS assessment tool. Findings of this study supported the use of transdiagnostic approaches in the assessment and treatment of psychological disorders. Moreover, dyadic disorder comorbidities of some anxiety disorders and MDE were found to increase the odds for having suicidal ideation, inadequate social support, and poorer quality of life than a diagnosis of only one of the two making up the dyadic disorder.

\section{Acknowledgments}

The authors would like to thank the Australian Government Department of Health and Ageing who provided the funding for the development of the Anxiety Online service. e-PASS and the Mental Health Online/Anxiety Online e-therapy treatment programs are available to the international public at no cost (fully automated self-help). The therapist-assisted version is open only to Australian residents at a minimal cost. The funders of Mental Health Online (Australian Government Department of Health and Ageing) had no other involvement in this study or report.

\section{Conflicts of Interest}

None declared.

\section{Multimedia Appendix 1}

Abbreviations for the 21 psychological disorders diagnosed by e-PASS.

[PDF File (Adobe PDF File), 29KB-Multimedia Appendix 1]

\section{Multimedia Appendix 2}

Table - Frequency of co-occurrences of 21 psychological disorders for males, females, and both.

[XLSX File (Microsoft Excel File), 20KB-Multimedia Appendix 2]

\section{References}

1. Kessler RC, Berglund P, Demler O, Jin R, Merikangas KR, Walters EE. Lifetime prevalence and age-of-onset distributions of DSM-IV disorders in the National Comorbidity Survey Replication. Arch Gen Psychiatry 2005 Jun;62(6):593-602. [doi: 10.1001/archpsyc.62.6.593] [Medline: 15939837] 
2. Kessler RC, Chiu WT, Demler O, Merikangas KR, Walters EE. Prevalence, severity, and comorbidity of 12-month DSM-IV disorders in the National Comorbidity Survey Replication. Arch Gen Psychiatry 2005 Jun;62(6):617-627 [FREE Full text] [doi: 10.1001/archpsyc.62.6.617] [Medline: 15939839]

3. Albert U, Rosso G, Maina G, Bogetto F. Impact of anxiety disorder comorbidity on quality of life in euthymic bipolar disorder patients: differences between bipolar I and II subtypes. J Affect Disord 2008 Jan;105(1-3):297-303. [doi: 10.1016/j.jad.2007.05.020] [Medline: 17617468 ]

4. Schoevers RA, Deeg DJH, van Tilburg W, Beekman ATF. Depression and generalized anxiety disorder: co-occurrence and longitudinal patterns in elderly patients. Am J Geriatr Psychiatry 2005 Jan;13(1):31-39. [doi: 10.1176/appi.ajgp.13.1.31] [Medline: 15653938$]$

5. Al-Asadi AM, Klein B, Meyer D. Comorbidity structure of psychological disorders in the online e-PASS data as predictors of psychosocial adjustment measures: psychological distress, adequate social support, self-confidence, quality of life, and suicidal ideation. J Med Internet Res 2014;16(10):e248 [FREE Full text] [doi: 10.2196/jmir.3591] [Medline: 25351885]

6. Farabaugh A, Fava M, Mischoulon D, Sklarsky K, Petersen T, Alpert J. Relationships between major depressive disorder and comorbid anxiety and personality disorders. Compr Psychiatry 2005;46(4):266-271. [Medline: 16175757]

7. National eTherapy Centre (n.d.). Swinburne University of Technology URL: https://www.anxietyonline.org.au/default. aspx [accessed 2015-02-22] [WebCite Cache ID 6WXMGIADE]

8. Andrews G, Anderson TM, Slade T, Sunderland M. Classification of anxiety and depressive disorders: problems and solutions. Depress Anxiety 2008;25(4):274-281. [doi: 10.1002/da.20489] [Medline: 18415950]

9. Brown TA, Barlow DH. Comorbidity among anxiety disorders: implications for treatment and DSM-IV. J Consult Clin Psychol 1992 Dec;60(6):835-844. [Medline: 1460147]

10. Marshall JR. Comorbidity and its effects on panic disorder. Bull Menninger Clin 1996;60(2 Suppl A):A39-A53. [Medline: 8857426]

11. Slade T, Watson D. The structure of common DSM-IV and ICD-10 mental disorders in the Australian general population. Psychol Med 2006 Nov;36(11):1593-1600. [doi: 10.1017/S0033291706008452] [Medline: 16882356]

12. Vollebergh WA, Iedema J, Bijl RV, de Graaf R, Smit F, Ormel J. The structure and stability of common mental disorders: the NEMESIS study. Arch Gen Psychiatry 2001 Jun;58(6):597-603. [Medline: 11386990]

13. Watson D, O'Hara MW, Stuart S. Hierarchical structures of affect and psychopathology and their implications for the classification of emotional disorders. Depress Anxiety 2008;25(4):282-288. [doi: 10.1002/da.20496] [Medline: 18415951]

14. Naragon-Gainey K. Meta-analysis of the relations of anxiety sensitivity to the depressive and anxiety disorders. Psychol Bull 2010 Jan;136(1):128-150. [doi: 10.1037/a0018055] [Medline: 20063929]

15. Zimmerman M, McDermut W, Mattia JI. Frequency of anxiety disorders in psychiatric outpatients with major depressive disorder. Am J Psychiatry 2000 Aug;157(8):1337-1340. [Medline: 10910803]

16. Rush AJ, Fava M, Wisniewski SR, Lavori PW, Trivedi MH, Sackeim HA, et al. Sequenced treatment alternatives to relieve depression (STAR*D): rationale and design. Control Clin Trials 2004 Feb;25(1):119-142. [Medline: 15061154]

17. Gorman JM. Comorbid depression and anxiety spectrum disorders. Depress Anxiety 1996;4(4):160-168. [doi: 10.1002/(SICI)1520-6394(1996)4:4<160::AID-DA2>3.0.CO;2-J] [Medline: 9166648]

18. Fava M, Alpert JE, Carmin CN, Wisniewski SR, Trivedi MH, Biggs MM, et al. Clinical correlates and symptom patterns of anxious depression among patients with major depressive disorder in STAR*D. Psychol Med 2004 Oct;34(7):1299-1308. [Medline: 15697056 ]

19. Axelson DA, Birmaher B. Relation between anxiety and depressive disorders in childhood and adolescence. Depress Anxiety 2001;14(2):67-78. [Medline: 11668659]

20. Brady EU, Kendall PC. Comorbidity of anxiety and depression in children and adolescents. Psychol Bull 1992 Mar;111(2):244-255. [Medline: 1557475]

21. Mackenzie CS, Reynolds K, Chou KL, Pagura J, Sareen J. Prevalence and correlates of generalized anxiety disorder in a national sample of older adults. Am J Geriatr Psychiatry 2011 Apr;19(4):305-315. [doi: 10.1097/JGP.0b013e318202bc62] [Medline: 21427639]

22. Roca M, Gili M, Garcia-Garcia M, Salva J, Vives M, Garcia CJ, et al. Prevalence and comorbidity of common mental disorders in primary care. J Affect Disord 2009 Dec;119(1-3):52-58. [doi: 10.1016/j.jad.2009.03.014] [Medline: 19361865]

23. Almeida-Filho N, Lessa I, Magalhães L, Araúho MJ, Aquino E, de Jesus Mari Jair. Co-occurrence patterns of anxiety, depression and alcohol use disorders. Eur Arch Psychiatry Clin Neurosci 2007 Oct;257(7):423-431. [doi:

10.1007/s00406-007-0752-0] [Medline: 17902002]

24. Fava M, Rankin MA, Wright EC, Alpert JE, Nierenberg AA, Pava J, et al. Anxiety disorders in major depression. Compr Psychiatry 2000;41(2):97-102. [Medline: 10741886]

25. Petersen T, Andreotti CF, Chelminski I, Young D, Zimmerman M. Do comorbid anxiety disorders impact treatment planning for outpatients with major depressive disorder? Psychiatry Res 2009 Aug 30;169(1):7-11. [doi:

10.1016/j.psychres.2008.10.036] [Medline: 19596155]

26. Atalay H. Comorbidity of insomnia detected by the Pittsburgh sleep quality index with anxiety, depression and personality disorders. Isr J Psychiatry Relat Sci 2011;48(1):54-59 [FREE Full text] [Medline: 21572244] 
27. Taylor DJ, Lichstein KL, Durrence HH, Reidel BW, Bush AJ. Epidemiology of insomnia, depression, and anxiety. Sleep 2005 Nov;28(11):1457-1464. [Medline: 16335332]

28. Liu X, Buysse DJ, Gentzler AL, Kiss E, Mayer L, Kapornai K, et al. Insomnia and hypersomnia associated with depressive phenomenology and comorbidity in childhood depression. Sleep 2007 Jan;30(1):83-90. [Medline: 17310868]

29. Tsuno N, Besset A, Ritchie K. Sleep and depression. J Clin Psychiatry 2005 Oct;66(10):1254-1269. [Medline: 16259539]

30. Ivanenko A, Crabtree VM, Gozal D. Sleep and depression in children and adolescents. Sleep Med Rev 2005 Apr;9(2):115-129. [doi: 10.1016/j.smrv.2004.09.006] [Medline: 15737790]

31. Hughes EK. Comorbid depression and anxiety in childhood and adolescent anorexia nervosa: Prevalence and implications for outcome. Clinical Psychologist 2012;16(1):15-24. [doi: 10.1111/j.1742-9552.2011.00034.x]

32. Swinbourne JM, Touyz SW. The co-morbidity of eating disorders and anxiety disorders: a review. Eur Eat Disord Rev 2007 Jul;15(4):253-274. [doi: 10.1002/erv.784] [Medline: 17676696 ]

33. Casper RC. Depression and eating disorders. Depress Anxiety 1998;8 Suppl 1:96-104. [Medline: 9809221]

34. Jordan J, Joyce PR, Carter FA, Horn J, McIntosh VVW, Luty SE, et al. Specific and nonspecific comorbidity in anorexia nervosa. Int J Eat Disord 2008 Jan;41(1):47-56. [doi: 10.1002/eat.20463] [Medline: 17868127]

35. Allen A, Hollander E. Similarities and differences between body dysmorphic disorder and other disorders. Psychiatric Annals 2004;34(12):927-933.

36. Teesson M, Slade T, Mills K. Comorbidity in Australia: findings of the 2007 National Survey of Mental Health and Wellbeing. Aust N Z J Psychiatry 2009 Jul;43(7):606-614. [doi: 10.1080/00048670902970908] [Medline: 19530017]

37. McGovern MP, Xie H, Segal SR, Siembab L, Drake RE. Addiction treatment services and co-occurring disorders: Prevalence estimates, treatment practices, and barriers. J Subst Abuse Treat 2006 Oct;31(3):267-275. [doi: 10.1016/j.jsat.2006.05.003] [Medline: 16996389$]$

38. Blinder BJ, Cumella EJ, Sanathara VA. Psychiatric comorbidities of female inpatients with eating disorders. Psychosom Med 2006;68(3):454-462. [doi: 10.1097/01.psy.0000221254.77675.f5] [Medline: 16738079]

39. Swanson SA, Crow SJ, Le Grange D, Swendsen J, Merikangas KR. Prevalence and correlates of eating disorders in adolescents. Results from the national comorbidity survey replication adolescent supplement. Arch Gen Psychiatry 2011 Jul;68(7):714-723. [doi: 10.1001/archgenpsychiatry.2011.22] [Medline: 21383252]

40. Hudson JI, Pope HG, Yurgelun-Todd D, Jonas JM, Frankenburg FR. A controlled study of lifetime prevalence of affective and other psychiatric disorders in bulimic outpatients. Am J Psychiatry 1987 Oct;144(10):1283-1287. [Medline: 3499087]

41. Iwasaki Y, Matsunaga H, Kiriike N, Tanaka H, Matsui T. Comorbidity of axis I disorders among eating-disordered subjects in Japan. Compr Psychiatry 2000;41(6):454-460. [doi: 10.1053/comp.2000.16561] [Medline: 11086152]

42. Salbach-Andrae H, Lenz K, Simmendinger N, Klinkowski N, Lehmkuhl U, Pfeiffer E. Psychiatric comorbidities among female adolescents with anorexia nervosa. Child Psychiatry Hum Dev 2008 Sep;39(3):261-272. [doi: 10.1007/s10578-007-0086-1] [Medline: 17987378]

43. Carter JD, Joyce PR, Mulder RT, Luty SE, Sullivan PF. Gender differences in the rate of comorbid axis I disorders in depressed outpatients. Depress Anxiety 1999;9(2):49-53. [Medline: 10207658]

44. Fava M, Abraham M, Clancy-Colecchi K, Pava JA, Matthews J, Rosenbaum JF. Eating disorder symptomatology in major depression. J Nerv Ment Dis 1997 Mar;185(3):140-144. [Medline: 9091594]

45. Godart NT, Flament MF, Perdereau F, Jeammet P. Comorbidity between eating disorders and anxiety disorders: a review. Int J Eat Disord 2002 Nov;32(3):253-270. [doi: 10.1002/eat.10096] [Medline: 12210640]

46. Pallister E, Waller G. Anxiety in the eating disorders: understanding the overlap. Clin Psychol Rev 2008 Mar;28(3):366-386. [doi: 10.1016/j.cpr.2007.07.001] [Medline: 17707562]

47. Godart NT, Flament MF, Curt F, Perdereau F, Lang F, Venisse JL, et al. Anxiety disorders in subjects seeking treatment for eating disorders: a DSM-IV controlled study. Psychiatry Res 2003 Mar 25;117(3):245-258. [Medline: 12686367]

48. Hinrichsen H, Wright F, Waller G, Meyer C. Social anxiety and coping strategies in the eating disorders. Eat Behav 2003 Aug;4(2):117-126. [doi: 10.1016/S1471-0153(03)00016-3] [Medline: 15000975]

49. Keel PK, Klump KL, Miller KB, McGue M, Iacono WG. Shared transmission of eating disorders and anxiety disorders. Int J Eat Disord 2005 Sep;38(2):99-105. [doi: 10.1002/eat.20168] [Medline: 16134107]

50. Lilenfeld LR, Kaye WH, Greeno CG, Merikangas KR, Plotnicov K, Pollice C, et al. A controlled family study of anorexia nervosa and bulimia nervosa: psychiatric disorders in first-degree relatives and effects of proband comorbidity. Arch Gen Psychiatry 1998 Jul;55(7):603-610. [Medline: 9672050]

51. Piran N, Kennedy S, Garfinkel PE, Owens M. Affective disturbance in eating disorders. J Nerv Ment Dis 1985 Jul;173(7):395-400. [Medline: 3859581]

52. Halmi KA, Sunday SR, Klump KL, Strober M, Leckman JF, Fichter M, et al. Obsessions and compulsions in anorexia nervosa subtypes. Int J Eat Disord 2003 Apr;33(3):308-319. [doi: 10.1002/eat.10138] [Medline: 12655628]

53. Bulik CM, Sullivan PF, Carter FA, Joyce PR. Lifetime anxiety disorders in women with bulimia nervosa. Compr Psychiatry 1996;37(5):368-374. [Medline: 8879912$]$

54. Godart NT, Flament MF, Lecrubier Y, Jeammet P. Anxiety disorders in anorexia nervosa and bulimia nervosa: co-morbidity and chronology of appearance. Eur Psychiatry 2000 Feb;15(1):38-45. [Medline: 10713801] 
55. Fornari V, Kaplan M, Sandberg DE, Matthews M, Skolnick N, Katz J. Depressive and anxiety disorders in anorexia nervosa and bulimia nervosa. International Journal of Eating Disorders 1992;12(1):21-29. [doi: 10.1002/1098-108X]

56. Garfinkel PE, Lin E, Goering P, Spegg C, Goldbloom DS, Kennedy S, et al. Bulimia nervosa in a Canadian community sample: prevalence and comparison of subgroups. Am J Psychiatry 1995 Jul;152(7):1052-1058. [Medline: 7793442]

57. Laessle RG, Kittl S, Fichter MM, Wittchen HU, Pirke KM. Major affective disorder in anorexia nervosa and bulimia. A descriptive diagnostic study. Br J Psychiatry 1987 Dec;151:785-789. [Medline: 3502805]

58. Schwalberg MD, Barlow DH, Alger SA, Howard LJ. Comparison of bulimics, obese binge eaters, social phobics, and individuals with panic disorder on comorbidity across DSM-III-R anxiety disorders. J Abnorm Psychol 1992 Nov;101(4):675-681. [Medline: 1430607]

59. Dansky BS, Brewerton TD, Kilpatrick DG, O'Neil PM. The National Women's Study: relationship of victimization and posttraumatic stress disorder to bulimia nervosa. Int J Eat Disord 1997 Apr;21(3):213-228. [Medline: 9097195]

60. Cororve MB, Gleaves DH. Body dysmorphic disorder: a review of conceptualizations, assessment, and treatment strategies. Clin Psychol Rev 2001 Aug;21(6):949-970. [Medline: 11497214$]$

61. Rauch SL, Phillips KA, Segal E, Makris N, Shin LM, Whalen PJ, et al. A preliminary morphometric magnetic resonance imaging study of regional brain volumes in body dysmorphic disorder. Psychiatry Res 2003 Jan 20;122(1):13-19. [Medline: 12589879]

62. Phillips KA. The broken mirror: understanding and treating body dysmorphic disorder. Oxford: Oxford University Press; 2005.

63. Conway KP, Compton W, Stinson FS, Grant BF. Lifetime comorbidity of DSM-IV mood and anxiety disorders and specific drug use disorders: results from the National Epidemiologic Survey on Alcohol and Related Conditions. J Clin Psychiatry 2006 Feb;67(2):247-257. [Medline: 16566620]

64. Rush B, Koegl CJ. Prevalence and profile of people with co-occurring mental and substance use disorders within a comprehensive mental health system. Can J Psychiatry 2008 Dec;53(12):810-821. [Medline: 19087479]

65. Klein B, Meyer D, Austin DW, Kyrios M. Anxiety online: a virtual clinic: preliminary outcomes following completion of five fully automated treatment programs for anxiety disorders and symptoms. J Med Internet Res 2011;13(4):e89 [FREE Full text] [doi: 10.2196/jmir.1918] [Medline: 22057287]

66. Gum AM, Cheavens JS. Psychiatric comorbidity and depression in older adults. Curr Psychiatry Rep 2008 Feb;10(1):23-29. [Medline: 18269891]

67. Moses EB, Barlow DH. A new unified treatment approach for emotional disorders based on emotion science. Current Directions in Psychological Science 2006;15(3):146-150. [doi: 10.1111/j.0963-7214.2006.00425.x]

68. Barlow DH, Allen LB, Choate ML. Toward a unified treatment for emotional disorders. Behavior Therapy 2004 Mar;35(2):205-230. [doi: 10.1016/S0005-7894(04)80036-4]

69. Al-Asadi AM, Klein B, Meyer D. Comorbidity structure of psychological disorders in the online e-PASS data as predictors of psychosocial adjustment measures: psychological distress, adequate social support, self-confidence, quality of life, and suicidal ideation. J Med Internet Res 2014;16(10):e248 [FREE Full text] [doi: 10.2196/jmir.3591] [Medline: 25351885]

70. McEvoy PM, Nathan P, Norton PJ. Efficacy of Transdiagnostic Treatments: A Review of Published Outcome Studies and Future Research Directions. J Cogn Psychother 2009 Feb 01;23(1):20-33. [doi: 10.1891/0889-8391.23.1.20]

71. McManus F, Shafran R, Cooper Z. What does a transdiagnostic approach have to offer the treatment of anxiety disorders? Br J Clin Psychol 2010 Nov;49(Pt 4):491-505. [doi: 10.1348/014466509X476567] [Medline: 19878622]

72. Wade TD, Bergin JL, Martin NG, Gillespie NA, Fairburn CG. A transdiagnostic approach to understanding eating disorders. J Nerv Ment Dis 2006 Jul;194(7):510-517. [doi: 10.1097/01.nmd.0000225067.42191.b0] [Medline: 16840847]

73. Andersson G, Titov N. Advantages and limitations of Internet-based interventions for common mental disorders. World Psychiatry 2014 Feb;13(1):4-11 [FREE Full text] [doi: 10.1002/wps.20083] [Medline: 24497236]

\author{
Abbreviations \\ ADIS: Anxiety Disorders Interview Schedule \\ AwoPD: agoraphobia without panic disorder \\ BDD: body dysmorphic disorder \\ DSM-5: Diagnostic and Statistical Manual of Mental Disorders (5th edition) \\ DSM-IV-TR: Diagnostic and Statistical Manual of Mental Disorders (4th edition, Text Revision) \\ e-PASS: electronic psychological assessment screening system \\ GAD: generalized anxiety disorder \\ MDD: major depressive disorder \\ MDE: major depressive episode \\ OCD: obsessive compulsive disorder \\ PD/A: panic disorder with or without agoraphobia \\ PTSD: posttraumatic stress disorder \\ SAD: social anxiety disorder
}


SP: specific phobia

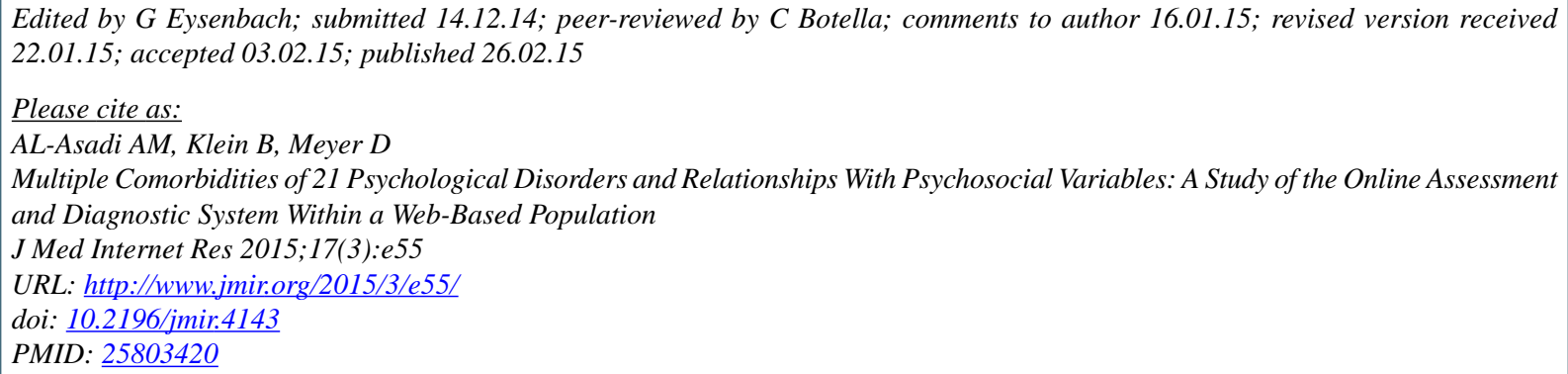

(C)Ali M AL-Asadi, Britt Klein, Denny Meyer. Originally published in the Journal of Medical Internet Research (http://www.jmir.org), 26.02.2015. This is an open-access article distributed under the terms of the Creative Commons Attribution License (http://creativecommons.org/licenses/by/2.0/), which permits unrestricted use, distribution, and reproduction in any medium, provided the original work, first published in the Journal of Medical Internet Research, is properly cited. The complete bibliographic information, a link to the original publication on http://www.jmir.org/, as well as this copyright and license information must be included. 